\title{
The subjective nature of Linnaean categories and its impact in evolutionary biology and biodiversity studies
}

\author{
Michel Laurin ${ }^{1,2}$ \\ ${ }^{1}$ UMR 7207 (CNRS/MNHN/UPMC), Department 'Histoire de la Terre', CP 48, 43 rue Buffon, F-75231 Paris \\ Cedex 05, France \\ ${ }^{2}$ E-mail:michel.laurin@upmc.fr
}

Key words: biological nomenclature, codes of nomenclature, comparative biology, evolution, PhyloCode, phylogenetic nomenclature

\begin{abstract}
Absolute (Linnaean) ranks are essential to rank-based nomenclature (RN), which has been used by the vast majority of systematists for the last 150 years. They are widely recognized as being subjective among taxonomists, but not necessarily in other fields. For this reason, phylogenetic nomenclature (PN) and other alternative nomenclatural systems have been developed. However, reluctance to accept alternative nomenclatural systems and continued use of higher taxa of a given Linnaean category in comparative analyses presumably reflect a lack of appreciation of the deleterious effects of the subjective nature of Linnaean categories in other biological fields, such as conservation and evolutionary biology. To make that point clearer, evolutionary models under which such categories would be natural are presented and are shown to be highly unrealistic and to lack empirical support. Under all realistic evolutionary models, ranking of taxa into Linnaean categories is highly subjective. Solutions that could make taxonomic ranks objective are surveyed. A review of the literature illustrates two problems created by the use of Linnaean categories in comparative or evolutionary studies, namely suboptimal taxonomic sampling schemes in studies of character evolution, and unreliable biodiversity assessment drawn on the basis of counting higher taxa (taxon surrogacy).
\end{abstract}

\section{Contents}

Introduction …….................................................................... 131

Evolutionary models and absolute ranks ............................. 134

Number of included terminal taxa .................................. 134

Geological age of origin .................................................... 135

Phenotypic distinctiveness ............................................ 136

Biological criteria for rank assignment at a given level ...... 136

Consequences of the subjective nature of

Linnaean categories ............................................................... 137

Imprecision in the meaning of taxonomic names ......... 137

Comparative studies that rely on supraspecific taxa ... 140

An explanation of the persistence of Linnaean categories

in biological nomenclature ............................................... 142

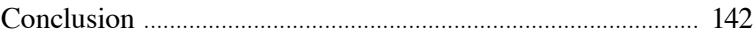

Acknowledgements ................................................................. 143

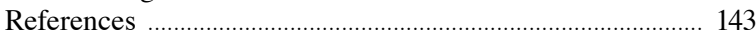

\section{Introduction}

Absolute ranks (Linnaean categories) are essential to rank-based nomenclature ( $\mathrm{RN})$, which is used in most codes of biological nomenclature. These include the International Code of Botanical Nomenclature or ICBN (Greuter et al., 2000), the International Code of Zoological Nomenclature or ICZN (International Commission on Zoological Nomenclature, 1999), and the International Code of Nomenclature of Bacteria or ICNB (Lapage et al., 1990), all of which are inspired by the Strickland code (Strickland et al., 1843). As such, Linnaean categories, first introduced by Linnaeus (Linnaeus, 1758; Schmitz et al., 2007), are the foundation of the nomenclatural system that has been used by the vast majority of systematists for the last 150 years. This is because under RN, definitions of taxon names consist solely of a type and a rank (De Queiroz and Cantino, 2001; Laurin, 2005, 2008; Lee and Skinner, 2007), although it can also be argued that these are not genuine definitions (Laurin, 2008: 228; Béthoux, 2010: 175) because they do not precisely delimit taxa (Fig. 1b-d). Definitions apply to names (such as taxon names), not to entities themselves; they identify the entity to which the name refers. Under the ICNZ, the nature of the type depends on the rank of the taxon (Fig. 1a); for species, types are specimens (biological organisms), but for genera and families, the type is a taxon of lower rank (a species typifies a genus, and a genus typifies a family). For instance, the taxon Hominidae in $\mathrm{RN}$ is nothing more than the taxon ranked as family having the genus Homo as its type, and Homo is simply the genus-level taxon that is typified by the species Homo sapiens Linnaeus 1758. Above the family-series, names are not typified under the ICZN. 
This system leads to ambiguous delimitation because Linnaean categories are widely known to be subjective (Griffiths, 1974, 1976; Minelli, 2000; Ereshefsky, 2002; Laurin, 2005). As summarized by Bertrand et al. (2006), rank allocation is complex and is dictated by many requirements, some of which conflict with each other, and none of which is absolute. These factors include monophyly (not required by any rankbased code), the rank of sister taxa, of more and less inclusive taxa, the number of included lower-ranking taxa (this number is often kept small enough for a systematist to remember taxon membership), phenotypic gaps, etc. Thus, ranking decisions are influenced by previous generations of systematists, but these ranking traditions may be highly variable between taxa since taxonomists often specialize in one or a few closely related taxa. For such reasons, ranking taxa into Linnaean categories is almost universally recognized as a fairly subjective exercise among taxonomists, and phylogenetic nomenclature (PN) and other alternative nomenclatural systems that do not require such categories (or that de-emphasize them) were proposed as more objective and natural alternatives (De Queiroz and Gauthier, 1990, 1992; Papavero et al., 2001; Cantino, 2004; Dubois, 2005a, b; Béthoux, 2007, 2010). Of these alternative systems, only one (PN) has been developed into a full-fledged code, the International Code of Phylogenetic Nomenclature (ICPN), also known as the PhyloCode (Cantino and De Queiroz, 2010). Linnaean categories play no role in PN (Fig. 1e-

\section{Original nomenclature \\ Alternative nomenclatures based on the same phylogeny}

(a)

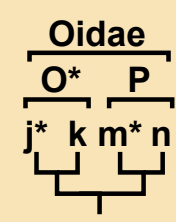

Recognition

of new

genera

(b)

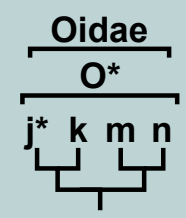

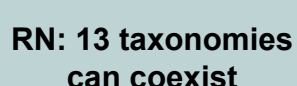

Synonymy can coexist

(c) Oidae
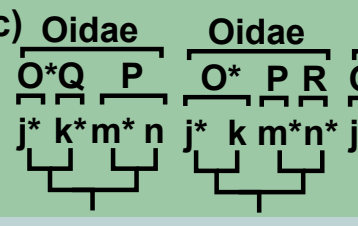

Oidae $\mathbf{O}^{*} \mathbf{Q} \mathbf{P} \mathbf{R}$
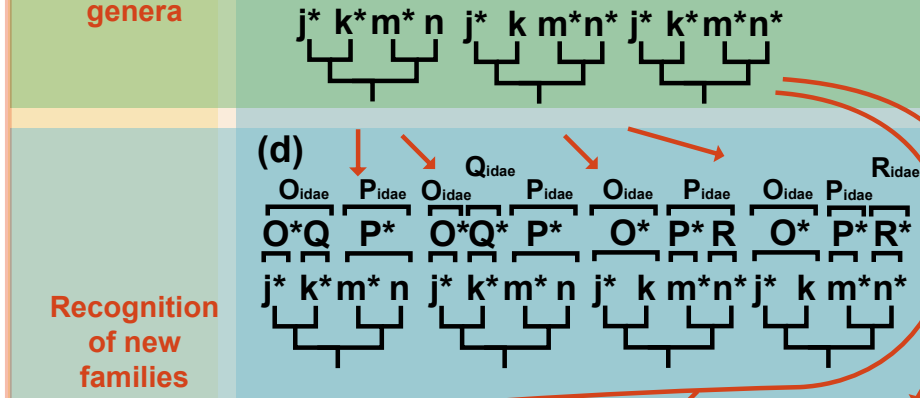

families
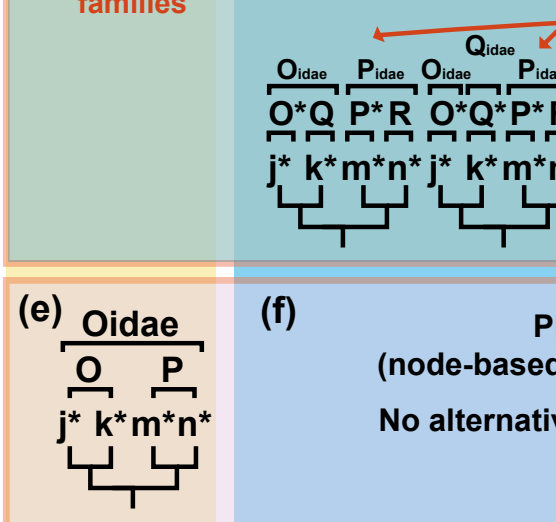

(f)

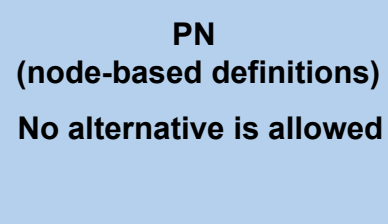

clades

clades

species

* speci-

fiers family

genus

species

* types

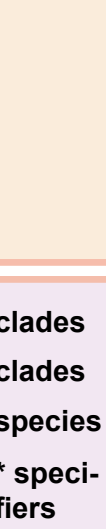

Fig. 1. Taxon name definitions and minimal taxonomic stability under rank-based (RN) and phylogenetic nomenclature (PN) when the phylogeny is stable. Under the original phylogeny and nomenclature in RN (a), four species are recognized $(j, k, m, n)$, two of which $(j, m)$ are types of genera. Two genera are recognized $(\mathrm{O}, \mathrm{P})$, one of which is the type of the family Oidae. All types are identified by an asterisk (*; holotypes of species not shown). Note that under RN 13 nomenclatures (the original one, and 12 other alternatives) can coexist simultaneously in the literature (all are valid according to the codes of $\mathrm{RN}$ ) because some taxa can be synonymised (b) and additional genera (c) and families (d) can be erected. This number would further increase if para- or polyphyletic taxa were erected. Under PN (e), four species $\mathrm{j}, \mathrm{k}, \mathrm{m}, \mathrm{n}$ and three higher taxa $(\mathrm{O}, \mathrm{P}$, Oidae) are recognized, two of which $(\mathrm{O}$, $\mathrm{P})$ include two species each, and one of which (Oidae) includes all four species, in the context of this phylogeny. Specifiers are identified by asterisks (*). Under $\mathrm{PN}$, all specifiers are specimens, species or characters. In this example, all definitions are node-based. Oidae is the smallest clade that includes $\mathrm{j}, \mathrm{k}, \mathrm{m}, \mathrm{n}$; $\mathrm{O}$ is the smallest clade that includes $\mathrm{j}$ and $\mathrm{k} ; \mathrm{P}$ is the smallest clade which includes $m$ and n. Under PN, no alternative nomenclature is allowed (f). Modified from Laurin (2008). 
f). Some authors dislike the name 'phylogenetic nomenclature' for the principles formalized in the ICPN because a nomenclature consistent with phylogeny can be proposed in the context of RN (Schuh, 2003). While the latter is true, $\mathrm{RN}$ does not ensure that nomenclature is phylogenetic because the $\mathrm{RN}$ codes allow paraphyletic and even polyphyletic taxa to be recognized, whereas this is forbidden by the ICPN. Furthermore, the name 'phylogenetic nomenclature' is now widespread and has been in use since the 1990s; I was able to trace it to Cantino et al. (1997), although this is not necessarily its earliest use. Therefore, it would be counterproductive to coin a new name for PN.

Reluctance of many systematists to adopt PN, and the continued use of higher-category taxa (i.e. taxa above the species level) in comparative studies (e.g. Benton et al., 2004; Moreno et al., 2008), suggest that some biologists are not entirely convinced that Linnaean categories are purely artificial, or that continued use of such categories has adverse effects in biology, even though many proponents of RN explicitly recognize the former (Dubois, 2005a, b; Benton, 2007). The pervasive use of categories is also demonstrated by a Google search for 'Class Mammalia', that yields 274 000 pages, whereas a search for 'Taxon Mammalia' yields only 2910 pages, nearly 100 times fewer entries (searches without the quotation marks may yield much greater numbers because both words may occur isolated, and these occurrences are not relevant to determining if Mammalia is considered a class or an unranked taxon). Searches in Google Scholar reveal a similar pattern: 5290 pages for 'Class Mammalia' and only 48 for 'Taxon Mammalia'. Finally, searches by topic in the ISI Web of Knowledge support the same pattern, with six papers with 'Class Mammalia' in the title, and none with 'Taxon Mammalia', 31 on the topic 'Class Mammalia', but none on the topic 'Taxon Mammalia' (all searches done on 22 May 2010). Thus, most laymen and scientists still appear to think that Linnaean categories convey information, even though most specialists of biological nomenclature realize that this is not the case.

The subjective nature of Linnaean categories is not relevant only to specialists of biological nomenclature. In the context of comparative studies, use of taxa belonging to a single higher category can at best impose unnecessary constraints (if, for consistency, taxa of a single level are sampled, which may mask interesting biological variation at lower levels), and can at worst produce spurious results (Bertrand et al., 2006). Although biological nomenclature has never been the primary occupation of a large proportion of biologists, comparative studies concern a large part of the biological community because they can tackle various evolutionary (Kriloff et al., 2008), ecological (Desdevises et al., 2003), and functional problems (Smith et al., 2009; Sakamoto et al., 2010). Comparative biology has recently benefitted tremendously from advances in phylogenetic inference methods (Goloboff et al., 2008), in statistical methods that incorporate phylogenetic information (Felsenstein, 1985; Desdevises et al., 2003), and in the development of user-friendly comparative analysis software (Maddison and Maddison, 2009), but it could also benefit from an integration of recent progress in biological nomenclature. Thus, a short demonstration of the arbitrary nature of Linnaean categories might be useful to many biologists (zoologists and botanists alike), especially evolutionary biologists and ecologists who use taxa in their analyses, but who are not specialists of biological nomenclature.

Many papers have discussed the advantages of phylogenetic nomenclature (e.g. Cantino et al., 1997; Brochu and Sumrall, 2001; Pleijel and Rouse, 2003), and about as many papers have voiced concerns about the introduction of this new nomenclatural system (e.g. Dyke, 2002; Dubois, 2006; Benton, 2007). The resulting lack of consensus and the moderate impact of such papers may result from their technical nature, as argued by Lee and Skinner (2007), and from the weight of tradition (Laurin, 2008). Nothing can be done about the weight of tradition, but to show the subjective nature of Linnaean categories in an accessible, non-technical way, I have chosen to open the argument with a presentation of the relationship between simple evolutionary models and Linnaean categories. A few proposed solutions to allocate ranks objectively are reviewed, and the impact of continued use of subjective ranks in evolutionary biology and biodiversity studies is examined. In the following discussion, I will assume that sister taxa should be of the same rank, as previously emphasized by proponents of rank-based nomenclature such as Dubois (2007a: 33), because only then can a coherent nomenclature be developed, in which a taxon of a given rank includes lower-ranking taxa, and is included in higher-ranking taxa. However, contra Dubois (2007a), I make no distinction between taxonomic categories and nomenclatural ranks because the ICZN (and the vast majority of practicing systematists) does not make that distinction, as recognized by Dubois (2007a: 27), and because assigning different nomenclatural and taxonomic ranks to a given taxon would be confusing. Indeed, below, I try 
to demonstrate that most nomenclatural ranks (the species is a possible exception) cannot be assigned unambiguously to taxonomic categories (sensu Dubois, 2007a).

\section{Evolutionary models and absolute ranks}

The criteria that have been, or could be, invoked to justify and determine absolute ranks include the geological age of origin, the number of included lowerranking taxa (or of species), and phenotypic distinctiveness. Simple examples should convincingly demonstrate that none of these criteria has ever been, nor ever could be, widely applied to determine absolute ranks.

\section{Number of included terminal taxa}

The number of included terminal taxa (usually called 'species') or of lower-ranking taxa could be used to determine ranks if the tree of life were completely symmetrical. In that case, we could adopt conventions to regulate the rank based on this criterion, possibly based on the $\log _{2}$ of the number of included terminal taxa (if we assume that cladogeneses systematically yield two rather than three or more daughter lineages). For instance, the number of species included could be 2 for species groups, 4 for subgenera, 8 for genera, 16 for subtribes, etc. (Fig. 2a). This could hold even if extinction subsequently eliminated some of these lineages. This convention might be workable if we had exhaustive knowledge of the tree of life (needless to say, this is far from being the case, except for extant members of some of the most intensively studied taxa). Unfortunately, nature does not produce symmetrical trees (Fig. 2b; Purvis and Agapow, 2002). It has been shown that the number of included genera in families is highly variable, ranging from one to more than 400 (Bertrand et al., 2006: fig. 2), and the same phenomenon prevails at other taxonomic levels, such as the number of genera per order, or the number of species per genus (Dial and Marzluff, 1989). Despite efforts in this direction (Van Valen, 1973), the number of included taxa of a given rank cannot be used to rank more inclusive taxa.

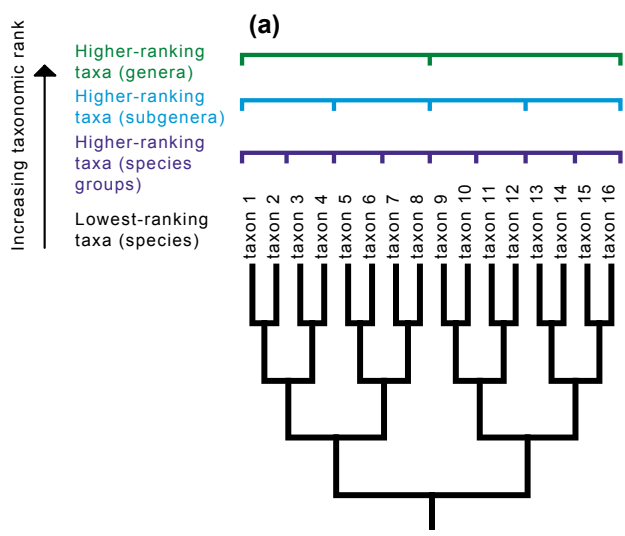

(b)

(c)

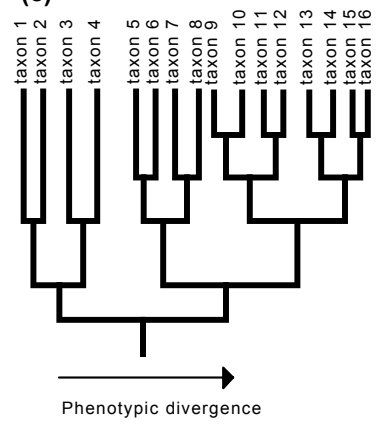

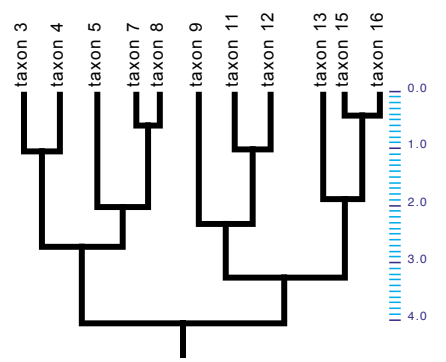

(d)

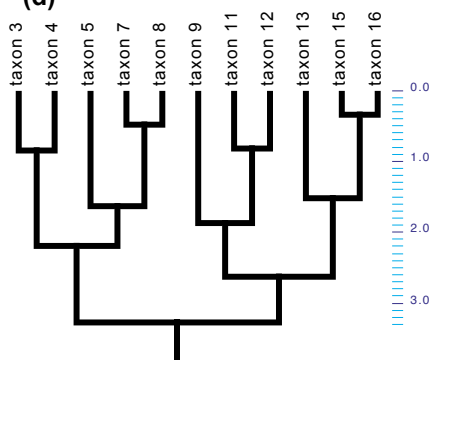

Fig. 2. Evolutionary models and Linnaean categories. Under a particular evolutionary model in which the phylogeny is symmetrical, in which cladogeneses occur concurrently and in which phenotypic gaps separating species can take only a limited number of discrete values, Linnaean categories could be claimed to be natural (a). Under more realistic models in which trees are asymmetrical and in which asynchronous cladogeneses generate phenotypic gaps of variable magnitude (b), Linnaean categories have no objective reality (there is no way to assign them objectively to taxa). Note that if only one of the three properties of the model shown in (a) prevailed, Linnaean categories could be assigned objectively. For instance, if cladogeneses were synchronous, but the tree were not symmetrical and phenotypic gaps between species could take any value (c), or if phenotypic gaps separating species took only a number of discrete values but the tree were not symmetrical and the cladogeneses were not synchronous (d), Linnaean categories could possibly be assigned objectively using the appropriate property of taxa (geological age of origin in (c), or phenotypic distance in (d). 


\section{Geological age of origin}

Perhaps the most frequently proposed criterion to rank taxa generally (not at a single taxonomic level) is geological age of origin of clades, and as such, it deserves a more detailed discussion. It was first proposed by Hennig (1966), and supported most recently by Avise and Mitchell (2007). Under that proposal, the geological age of origin of the least inclusive node subtending all terminal taxa of a clade (or even possibly paraphyletic group) would determine the rank of that taxon. For this purpose, geological times would be subdivided into a number of periods that could (but need not) coincide with currently recognized geological periods. The tremendous advantage of this proposal is that taxa of a given rank would have comparable ages of origin, a feature that would vastly improve usefulness of biological classifications in evolutionary studies, as emphasized by Avise and Johns (1999). The main drawback of this proposal is that it would require numerous changes in rank allocations, and this probably explains why this proposal has not been more generally followed, although some studies applied its principles to suggest rank allocation of a few taxa (Lim, 2007; Tinn and Oakley, 2008). The more recent proposal by Avise and Mitchell (2007) is aimed at avoiding this problem; it consists in appending timeclips to taxa (ranked or not). These could take the form of a three-letter code within brackets, such as [G:pa] to denote a clade originating in the Paleocene (the particular temporal divisions adopted and corresponding codes were left open by the authors). Thus, as this temporal information becomes available through molecular (e.g. Hugall et al., 2007) or paleontological dating (e.g. Maranović and Laurin, 2007), it could be incorporated into taxonomies. Under this latest proposal, rank allocation would not need to be changed to reflect the geological age of origin (although it could be done if the systematic community chose to do it), so it would not create taxonomic confusion. However, unless categories were reassigned to reflect age of origin, they would remain ontologically empty. The useful ranking information would reside entirely in the timeclips, rather than in the Linnaean categories.

The geological age of origin would be optimal to determine ranks if taxa originated in a synchronous, periodic (but not necessarily regular) manner. Suppose, for instance, that the first cladogenesis in a lineage occurs at time t. The next cladogenesis in both descendents occurs at time $\mathrm{t}+\mathrm{cl}$ ( $\mathrm{cl}$ is a constant). The four resulting lineages speciate again at time $t+c 2(c 2$ is another constant). In such a case (Fig. 2a), since several taxa appear simultaneously, their age of origin could be used to determine their rank. Unfortunately, cladogeneses do not appear to be coordinated in such ways (Fig. 2b). Nothing in modern evolutionary theory (Lee and Doughty, 2003; Minelli, 2007; Padian, 2008) predicts that cladogeneses should be simultaneous. The age of origin of taxa is often difficult to determine, but both molecular (Sanderson, 2002; Hedges and Kumar, 2009; Hugall et al., 2007) and paleontological dating (Marjanović and Laurin, 2007, 2008) suggest that asynchronous cladogeneses are the rule. There are periods of intense cladogenesis, for instance when taxa invade new niches (Ward et al., 2006), or after mass extinction has emptied ecological niches (Bromham, 2003), but these presumably represent periods of dense, asynchronous cladogenetic events.

Ranks traditionally attributed to taxa certainly do not reflect geological age, as shown by even a cursory glance at the literature. Extinct organisms of any geological age are usually attributed to taxa of all five 'mandatory' categories (genus, family, order, class, and phylum), in addition to a taxon of species rank (Laurin, 2005). Thus, the oldest species is as old as life itself, and so is the oldest genus, family, order, class, and phylum. Even if we exclude extinct organisms (a decision that would be difficult to justify but that might somewhat improve the correlation between taxonomic rank and geological age of origin), the geological age of taxa of any given rank is highly variable. In these comparisons, the age of origin of a taxon will be taken as the age of its basal node (i.e. the age of its oldest fossil member, or the nodal age inferred by molecular dating), rather than the age of its stem, although changing this choice would only make all taxa older without changing the age difference between them much. Sirenidae (ranked as a family), a clade of aquatic salamanders, originated in the Early or Late Cretaceous (about 80 to $110 \mathrm{Ma}$ ago), depending on whether or not some extinct forms are included (Marjanović and Laurin, 2007: fig. 3). Hominidae (also a family under rankbased nomenclature) originated about $7 \mathrm{Ma}$ ago in the Miocene, if it is defined as the largest clade that includes Homo sapiens but not Pan troglodytes (Linnaeus, 1758), the chimpanzee (Pilbeam and Young, 2004), so it is at least 10 times more recent. Some lissamphibian genera (Amphiuma, Necturus, Dicamptodon) appeared in the Paleocene (Marjanović and Laurin, 2007: fig. 4), about $60 \mathrm{Ma}$ ago, whereas the genus Homo dates from less than $3 \mathrm{Ma}$ (Semaw et al., 2005). Clearly, the geological age of origin of taxa of a given 
rank is highly variable; changing rank allocation to improve the correlation between age and rank would result in so many, and so drastic, nomenclatural changes that this solution will surely appear unsatisfactory to most systematists.

\section{Phenotypic distinctiveness}

Finally, phenotypic distinctiveness could be used to determine absolute ranks objectively (Mayr and Ashlock, 1991) if nature proceeded by discrete steps, or by gradual evolution under special circumstances (for instance, if cladogeneses were synchronous and if evolution proceeded at a steady rate). For instance, under a speciational or punctuated model of evolution, if the amount of phenotypic change could take only a few discrete values (not necessarily multiples of each other), phenotypic change could be used to assess the absolute rank of daughter lineages, at least for a small set of taxa (Fig. 2a). However, neither evolutionary theory nor observations corroborate any such evolutionary model; instead, the magnitude of phenotypic gaps appear to be highly variable (Fig. 2b). Even when the evolutionary model appears to be speciational or punctuated (Cubo, 2003; Mattila and Bokma, 2008), there is no evidence that the amount of phenotypic (or even genotypic) change takes a limited number of values, and of course, in most cases, gradual evolution presumably plays an important role, instead of, or in addition to, speciational change. Thus, phenotypic distinctiveness cannot be used to assess absolute ranks. It is difficult to show that phenotypic distinctiveness is highly variable between taxa, because it is difficult to quantify, but the very fact that it has not been quantified for most taxa (see Wills et al., 1994, for some exceptions) suggests that it has not been used as a criterion to rank taxa, or if used, only very imprecisely so.

If any regularity in the evolutionary model prevailed (if cladogeneses were synchronous, or if the tree were symmetrical, or if phenotypic gaps were discrete), ranks could perhaps be assigned objectively (Fig. 2c, d). However, as the above review shows, evolutionary theory and observations fail to confirm any of these special models. This leaves us without general rules to potentially assign ranks objectively.

\section{Biological criteria for rank assignment at a given level}

Some criteria have been proposed to rank taxa at a single rank. For instance, many authors define species as reproductive communities (Lee, 2003), or lineages of such reproductive communities (De Queiroz, 1998); Dubois (1988) defines the genus as a set of potentially hybridizing species; phyla are often considered to be defined by a unique body plan (Erwin et al., 1997; McHugh, 1997; Valentine, 2004). Between the genus and the phylum levels, I am not aware of any proposed objective criterion to rank taxa. Of these three ranks, the species seems to be recognized by the least subjective criterion, since most biologists would recognize that reproductive communities should play a role in their delimitation, although there is considerable variability about the importance and way in which this criterion is used, and some authors view species as subjective entities (Ereshefsky, 2002). For phyla, uniqueness of body plan is only a vague criterion that has generally neither been used in a precise way nor quantified. The proposal to define the genus level using hybridization can illustrate the more general problem of making Linnaean objective, since this rank has received the most attention, after the species level (Dubois, 1988, 2007a: 32).

Using hybridization capability to objectively assign ranks to taxa could in theory be done, although this would require many nomenclatural changes, as Dubois (1988: 40) recognized. Dubois (1988: 40) also admitted that the geological age of the taxa thus delimited would be highly variable, about 2-3 Ma for placental mammals, but 20-23 Ma for birds and anurans. Thus, implementing this suggestion would make genera comparable only in some respects (possibility of hybridization) but not in others (geological age, and, possibly, phenotypic divergence), in addition to being very costly (since millions of experiments would need to be conducted). Such an implementation would be technically difficult because two distantly related species may retain their ancestral ability to reproduce, while more closely related species of the same clade may have lost this ability. Dubois (1988) suggested that the capacity to hybridize reflected overall genetic similarity (of structural and regulation genes), which is plausible, but it is also known that reproductive isolation can arise rapidly in hybrids or polyploids (Venditti and Pagel, 2010: 18). Application of this reproductive criterion to some taxa would be difficult, if not strictly impossible. For instance, neither reproductive communities nor sets of potentially hybridizing species can be recognized for extinct organisms represented only by fossils, nor for asexual taxa, such as eubacteria, archeans, and some eukaryotes. Finally, other authors disagree with 
the application of the potential for hybridization to delimit taxa because it is based on shared primitive features whose loss may not be particularly significant (Lherminier, 2009).

Dubois (1988: 31) suggested that the origin of new genera involved a special process (called 'geniation') involving a genetic revolution, and that this process was distinct from that of other speciations. Such a distinct process would help to delimit genera (if defined as sets of species capable of hybridization), although some of these delimitations would presumably yield paraphyletic taxa, and no theoretical or empirical justification for the existence of a geniation process can be found in modern genetics. Genetic theory predicts that, in some cases, reproductive isolation evolves gradually. Although genetic revolutions may play an important role in some speciations - according to some analyses, about $20 \%$ of the genetic divergence result from cladogeneses rather than anagenetic change (Venditti and Pagel, 2010: 15) -, some authors have expressed doubt about the general importance of genetic revolutions (Lherminier, 2009: 44). Genetic revolutions are involved in cases of hybridization and autopolyploidy (Turelli et al., 2001: 334), or when founder effects are important (Bush, 2007: 376), but these may consist of simple allelic frequency changes that do not result in reproductive isolation (Excoffier and Ray, 2008). Thus, the use genetic revolutions to delimit genera may not be easier than application of the hybridability criterion.

\section{Consequences of the subjective nature of Linnaean categories}

The non-equivalence of taxa of a given rank has long been acknowledged as a major problem of rank-based nomenclature (Dubois, 1988), and interesting proposals to assign ranks objectively (Dubois, 1988; Avise and Johns, 1999) or to bypass the problem caused by the lack of objectivity of Linnaean categories (Avise and Mitchell, 2007) have been devised by systematists. Despite this, Linnaean categories continue to be widely used in evolutionary biology and biodiversity studies (see below). This creates several problems that have already been discussed (e.g. Rowe and Gauthier, 1992; Laurin, 2005, 2008; Bertrand et al., 2006), so only a brief summary needs to be presented here. The main problems created by absolute ranks fall mostly into two categories: instability in delimitation of taxa, with the resulting imprecision in meaning of taxonomic names and the need to specify membership of taxa in each study (Rowe and Gauthier, 1992; Laurin, 2005, 2008), and problems in comparative studies or biodiversity assessments that rely on any supraspecific taxa (De Queiroz and Donoghue, 1988: 334; Bertrand et al., 2006). Other, smaller problems include the proliferation of redundant taxon names, and the unnecessary change in taxonomic composition created by the application of the principle of priority within ranks (or coordinated sets of ranks).

\section{Imprecision in the meaning of taxonomic names}

Given that the absolute rank assignment of taxa is subjective, ranking and delimitation of taxa can vary substantially between authors, or even between papers by a single author. This problem can affect any biological field, because biological knowledge is usually taxon-specific; more than 1.5 million species have been described, and there are probably between 3.5 and 10.5 million extant species (Alroy, 2002). Thus, most biological knowledge is useful to the extent that the clade to which it applies is known with some precision. No objective reason for changing the rank allocation of a taxon, or for attributing a ranked taxon to another clade than specified in the original study is required by any of the rank-based codes. Similarly, the rank-based codes allow taxa to be put into synonymy (Fig. 1b) or for additional taxa to be erected within previously recognized taxa (Fig. 1c, d) without any justification or change in our objective knowledge about nature (i.e. discovery of new species or change in our understanding of the phylogeny). Thus, to take a simple hypothetical example consisting of four species $(j-n)$ forming two genera $(\mathrm{O}$ and $\mathrm{P})$ and one family (Oidae) under the originally proposed nomenclature (Fig. 1a), twelve alternative, equally, simultaneously and indefinitely valid nomenclatures can be proposed (Fig. 1b-d), resulting in thirteen nomenclatures. Under that system, the delimitation of taxa is ambiguous; hypothetical genus $\mathrm{O}$ can include species $\mathrm{j}$ and $\mathrm{k}$, as in the original nomenclature, but it can also include only its type species j (Fig. 1c) or species j-n (Fig. 1b). The delimitation of family Oidae can fluctuate in the same way. The number of possible nomenclatures increases very fast with the number of taxa considered, so this number must be extremely high for the biodiversity that is already known. This problem occurs even in the case in which the phylogeny is stable and in which no new species is discovered, a combination of circumstances that should lead to maximal nomenclatural stability. 
Much confusion arose in the discussions of nomenclatural stability in PN and RN because three kinds of nomenclatural stabilities (maximal, minimal, and realized) were conflated. Some proponents of $\mathrm{RN}$ have argued that the lack of precision in delimitation in $\mathrm{RN}$ is an advantage because it allows the limits of taxa to be adjusted when the phylogeny changes and when new taxa are discovered (Benton, 2007). This argument rests on the untested assumption that systema- tists spontaneously agree on the name and delimitation of taxa; if this were true, no system of biological nomenclature would be required. This is the maximal nomenclatural stability allowed by the system (Laurin, 2008), and it is undeniably greater than under PN, but it is seldom achieved, as empirical examples provided below demonstrate. The minimal nomenclatural stability provided by a system, if users abide by its rules, is probably more relevant, and it is in this respect that

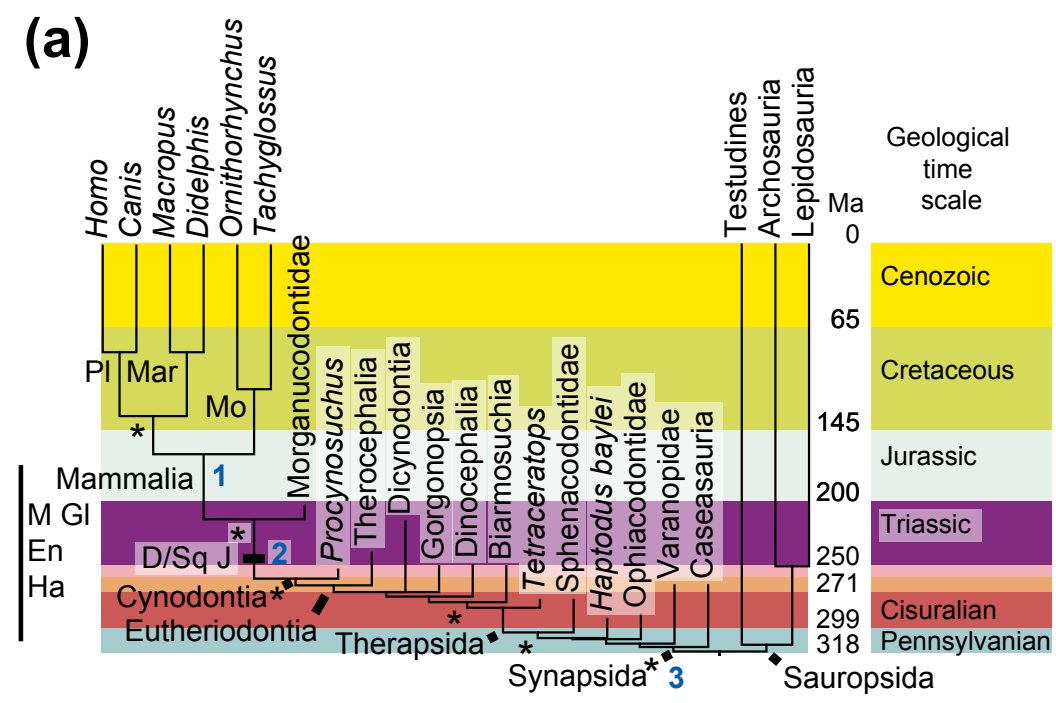

(b)
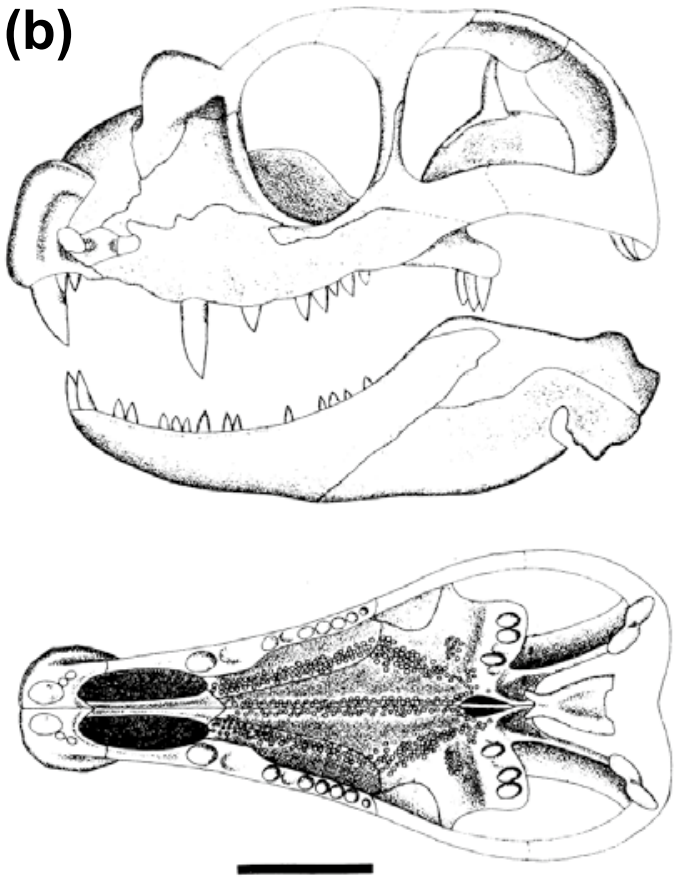

(c)
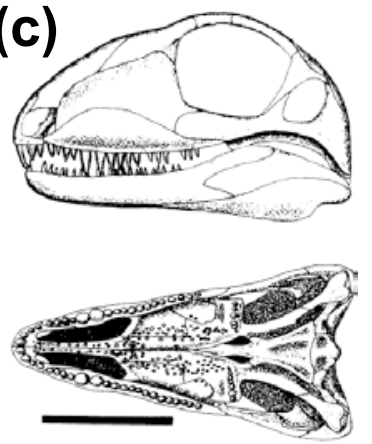

(d)

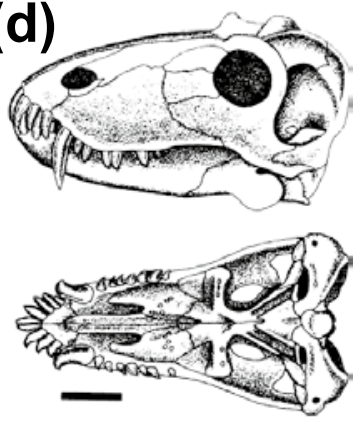

Fig. 3. Delimitation of the taxon Mammalia under rank-based (RN) and phylogenetic nomenclature (PN). Under RN, the name Mammalia (a) has been applied to several nested clades (some of which are identified by an asterisk), as shown by Rowe and Gauthier (1992). Under PN, the name could be defined using a crown-, apomorphy-, or total clade definition (numbers 1-3 in bold, blue type), but, once published in conformity with the PhyloCode, one definition would have priority and would not change. Most proponents of PN use a crown-clade definition of Mammalia (as shown here), but many proponents of $\mathrm{RN}$ have advocated using the appearance of the dentary/squamosal joint to delimit Mammalia, although this proposal has not been consistently followed. The possible time of appearance of several other mammalian characters is shown. The vertical bar denotes the considerable uncertainty that surrounds the time of origin of most non-skeletal 'mammalian' characters, which are known in the crown, but whose presence in other members of more inclusive taxa (e.g. Cynodontia, Eutheriodontia, Therapsida) cannot be assessed. A few taxa that have been occasionally considered part of Mammalia under RN are illustrated: Tetraceratops (b), Haptodus (c), and the dinocephalian Titanophoneus (d). Modified from Laurin and Cantino (2007) and Laurin and Reisz (1990). Scale bar (b-d) equals $2 \mathrm{~cm}$. The geological time scale is from Gradstein et al. (2004). The two periods that could not be labeled on the figure because of lack of space are (from bottom to top) the Guadalupian and Luopingian (Middle and Late Permian). Abbreviations: D/Sq J, dentary-squamosal joint; En, endothermy; Ha, hair; M Gl, mammary glands; Ma, million year ago; Mar, Marsupialia; Mo, Monotremata; Pl, Placentalia. 
PN vastly outperforms RN because under a given phylogeny, only one delimitation of each taxon is generally possible (Fig. 1e, f). The debates between proponents of RN and PN can thus be reformulated in terms of the relative importance of minimal and maximal nomenclatural stability. Which one should be maximized? Minimal stability should be maximized if taxonomists generally fail to spontaneously agree on taxon delimitation, but maximal stability should be maximized if systematists generally agree on taxon delimitation. To determine which situation prevails, case studies of the realized nomenclatural stability are needed, and a few are provided below. However, various statements in the literature suggest that spontaneous agreement on nomenclatural matters is rare; after all, 'It has been said that most scientists would rather use another scientist's toothbrush than his terminology' (McShea, 2000: 330).

Empirical studies show that the lack of delimitation provided by $\mathrm{RN}$ result poor realized nomenclatural stability, although this has been thoroughly investigated for few taxa. For instance, Rowe and Gauthier (1992) showed that the delimitation of Mammalia (ranked as a class, in rank-based nomenclature) has varied greatly between authors, and even between various studies by a given author (Fig. 3a). The least inclusive clade called 'Mammalia' in the literature that they surveyed is usually called Theria (the smallest clade that includes placentals and marsupials), and the most inclusive Synapsida (the largest clade that includes mammals but not extant reptiles). The difference in composition between the least and most inclusive clades thus called Mammalia is modest if only extant forms are included because Monotremata was the only extant taxon that has been excluded by a small minority of studies. However, when extinct forms are considered (Fig. 3b-d), the difference is great, no matter which criterion is emphasized. For instance, the time of origin of the least inclusive clade (Theria) is no earlier than Jurassic according to some molecular dating studies (Bininda-Emonds et al., 2007), and the paleontological evidence suggests an even later (Early Cretaceous) age of about $130 \mathrm{Ma}$ (Benton and Donoghue, 2007). At the other extreme, Synapsida is known to have originated in the Carboniferous, at least about 315 Ma ago (Marjanović and Laurin, 2007). When looking at the morphology, the diversity of aspects encompassed by the first mammal is also impressive. At one extreme, the first therian was probably a moderately small (less than $25 \mathrm{~cm}$ snout-vent length; $\mathrm{Hu}$ et al., 2005), possibly nocturnal, viviparous form with mammary glands and fur (Carroll, 1988). At the other extreme, the first synapsid was probably oviparous, devoid of mammary glands, diurnal, hairless, and larger, with a snout-vent length of about $34 \mathrm{~cm}$ (Laurin, 2004).

It could be argued that in the case of Mammalia, rank-based nomenclature could not stabilize their delimitation only because, under the ICZN, taxa above the family-series have no types. However, two facts refute this argument. Firstly, the ICZN and the ICNB clearly state that rank-based nomenclature does not delimitate taxa. Thus, according to Principle 2 in the introduction of the ICZN (1999), '[n]omenclature does not determine the inclusiveness or exclusiveness of any taxon, nor the rank to be accorded to any assemblage of animals, but, rather, provides the name that is to be used for a taxon whatever taxonomic limits and rank are given to it.' General Consideration 4 of the ICNB likewise states that '[r]ules of nomenclature do not govern the delimitation of taxa...' (Lapage et al., 1990). Thus, rank-based nomenclature seems to have been designed specifically to avoid delimiting taxa. This is perplexing because at least some proponents of rank-based nomenclature suggest that nomenclatural stability 'would certainly be greatly appreciated by non-systematists' (Dubois, 1988: 31). Secondly, problems in delimitation similar to those evoked above for Mammalia also plague lower-ranking taxa in the family- and genus-series. For instance, Keesey (in Laurin and Bryant, 2009) showed that names typified by Homo or Homo sapiens were associated with two (Hominoidea) to six (Hominidae) nested clades. Similar problems have affected names in the genus Rana (Hillis and Wilcox, 2005; Frost et al., 2006; Dubois, 2007b). In this case, the problem is exacerbated by the low number of Linnaean categories available to describe the diversity of the very speciose genus Rana (over 1000 species). Because of this, Hillis and Wilcox (2005) erected subgenera within subgenera, but, as pointed out by Dubois (2007b), this is contrary to the basic principles of rank-based nomenclature (although the ICZN, contrary to the ICNB, does not state this clearly). Proponents of rank-based nomenclature have long recognized that delimitation of taxa under that system is unstable, even at ranks at which taxa have types under the ICZN, such as the genus (Dubois, 1988). This brief review hopefully shows that the subjective nature of Linnaean categories contributes to vagueness in the meaning of taxon names, which is hardly surprising given that the authors of the rank-based codes apparently think that taxa should be left undelimited. 


\section{Comparative studies that rely on supraspecific taxa}

Using rank-based nomenclature can lead to various problems that concern especially evolutionary biology. These include placing unnecessary constraints on the taxonomic sample and placing undue confidence in absolute or relative biodiversity indices derived from counts of higher taxa, an approach called taxonomic surrogacy. The first problem can occur when taxa of a given rank are selected to trace the evolution of a character. For instance, Smith et al. (2009: fig. 3) inferred the evolution of the cecal appendix in mammals using 79 taxa ranked as families, in addition to Amphibian and Reptilia (usually ranked as classes). While the use of taxa of a given rank (families) gives the reassuring appearance of a homogeneous sampling effort, this was probably not the best strategy because the appendix evolved much faster in some taxa than in others. Thus, in Laurasiatheria, a major clade of placental mammals that probably originated near the $\mathrm{K} / \mathrm{T}$ boundary (about $65 \mathrm{Ma}$ ago), the appendix never appeared. In Euarchontoglires (another large clade of placentals originating near the $\mathrm{K} / \mathrm{T}$ boundary), the appendix evolved so fast that inferring its evolution using character optimization is difficult. In several of the 'families', the appendix was scored as 'variable' (usually termed 'polymorphic') when only some species in the taxon had an appendix (Smith et al., 2009: 1992). A more accurate estimate of the character history would have been obtained by replacing the polymorphic terminal taxa by smaller clades (typically ranked as genera) showing a single state. Thus, in this case, use of Linnaean categories gave unjustified confidence in a suboptimal taxonomic sampling scheme.

The problems raised by taxon surrogacy are even more acute. Prance (1994) showed that the neotropical region has a much greater biodiversity of embryophytes than equivalently sized paleotropical regions at the species level (Table 1). Looking at biodiversity at the genus or family level suggests that the flora of Africa and Malesia is about as diverse as that of the neotropics. It might be tempting to accept the conclusion that the neotropics support a greater biodiversity than the paleotropics based on Prance's (1994) data, but this may not be justified. Perhaps systematists working in the neotropics were just more extreme 'splitters' when erecting species (or they may have erected a greater proportion of subjective synonyms) than those working in the paleotropics. Conversely, perhaps botanists working in the paleotropics preferred to include fewer species in each genus and family than
Table 1. Biodiversity of embryophytes of the Neotropics and Paleotropics. Modified from Prance (1994).

\begin{tabular}{lrrr}
\hline & \multicolumn{3}{c}{ number of taxa at a given level in each region } \\
\hline taxonomic level & Africa & Malesia & Neotropic \\
\hline family & 271 & 310 & 292 \\
genus & 3750 & 3250 & 4200 \\
species & $40,000-45,000$ & 42,000 & 90,000 \\
\hline
\end{tabular}

botanists working in the neotropics, a question that has long divided systematists (Dubois, 1988); in this case, the neotropics might really have a greater biodiversity than the paleotropics. Another possibility is that the neotropics are home to a greater proportion of geologically recent species, which would explain that the number of genera and families is no higher in the neotropics than in the paleotropics. If Linnaean categories approximately reflected geological time, the three levels (species, genus, and family) would tell us something about the biodiversity of paleo- and neotropics. Unfortunately, this correlation, if present at all, seems to be very weak (Laurin, 2005; Bertrand et al., 2006), and rank assignment of taxa is too subjective to be informative. Bertrand et al. (2006: table 1) provided a compelling example of this using annelids.

Other studies have also found that using taxa of a given category to predict the biodiversity at a lower taxonomic level is problematic. For instance, Andersen (1995) showed that the number of ant genera in Australian localities was rather poorly correlated $\left(r^{2} \cong 0.5\right)$ with the number of species, and that the regression coefficient varied between habitats, size of area surveyed, and sampling effort, thus complicating the use of genus count to predict species counts. Grelle (2002) reported a fairly good correlation between the number of species and that of genera of neotropical mammals $\left(r^{2}=0.8\right)$ in various localities, but this varied strongly between taxa. Explained variance ranged from 0.45 for rodents to 0.96 for primates. Family and order number were generally not significantly correlated with species numbers. These patterns largely reflect the number of species per genus, family, and order, in taxonomies and in localities. As Grelle (2002) suggested, genus richness is often a good predictor of species richness when most genera are represented by one or two species in each locality. As that number increases, precision of the estimate of species number decreases. Thus, Terlizzi et al. (2003: 558) noted that ' $[t]$ he response of different taxonomic levels might change according to biogeographical features and internal diversity of taxa'; thus, 'if the 
family richness is a good surrogate of species diversity in the North Sea, it might not be the same for the Mediterranean sea'. This conclusion is confirmed by the subjective nature of Linnaean categories, but the very fact that studies are still done on the efficiency of taxon surrogacy suggests that the subjective nature of absolute ranks is not fully understood by many biologists. Terlizzi et al. (2003: 559) concluded that taxonomic surrogacy 'may be tolerated only when difficulties in sampling, data analysis and identification of some particular organisms make this procedure strictly necessary, not merely to save costs whatever the aim of the study is', and appropriately noted that '[i]f species loss is the main concern of conservation biology (together with habitat loss), it is simply absurd to pretend to perform conservation studies without considering species.'

The lack of unified concepts of individual Linnaean categories precludes interpretation of patterns found through taxon surrogacy. For instance, Grelle (2002: $105)$ reported that, in most neotropical localities, primates and marsupials were generally represented by a single species in each genus (but several genera per locality); in contrast, several species of bats and rodents represented each genus. Grelle (2002) suggested that these differences reflected a higher turnover of primate and marsupial species than of bats and rodents. This is not likely because bats (1100 species) and rodents (2277 species) are the most speciose clades of placental mammals (5400 species, approximately; species counts from Wilson and Reeder, 2005), and since their antiquity is approximately equal with that of primates and less than that of marsupials (Wible et al., 2007), the diversification rate of bats and rodents has obviously been higher than that of most other mammalian clades (marsupials and primates have about 334 and between 190 and 350 species, respectively). Similarly, Grelle's (2002: 105) suggestion that the difference in pattern between primates and marsupials on one hand, and rodents and chiropterans on the other, reflects 'different assembly rules organizing (or not) these communities' is not fully warranted. Such an interpretation might possibly be validated if it were shown that the minimal divergence time between primate or marsupial species co-occurring in localities were significantly different from that of rodent or chiropteran species that co-occur in similar localities. An alternative interpretation would be that ecological divergence allowing habitat sharing occurs faster in some of these taxa than in others. But such conclusions must rest on time-calibrated trees, not on 'ontologically empty' (Ereshefsky, 2002: S309) Linnaean categories.
Even the species level is not completely objective in the absence of a universally agreed-upon and universally applied species concept, and Ereshefsky (2002) has forcefully argued that this Linnaean category is as subjective as any other, even among sexually reproducing organisms. Furthermore, the equivalence between species of sexually reproducing organisms and asexual ones is even more problematic (Turelli et al., 2001: 336). Pleijel and Rouse (2003) even argued that we should drop the term 'species' and use the more ontologically neutral term LITU (least inclusive taxonomic unit) instead to denote the smallest recognizable clades. Thus, it could be argued that even counting species is not adequate to assess biodiversity, and that more objective indices based on phylogenies and evolutionary time should be used, such as Faith's (1992) phylogenetic diversity index (PDI). The PDI is simply the sum of branch lengths linking all terminal taxa (of an area, or a clade, or of any group of taxa of interest). Computing the PDI is now feasible for many taxa since user-friendly software such as Mesquite (Maddison and Maddison, 2009) can compute it, at least with some optional modules (Josse et al., 2006). The only remaining difficulty is obtaining a phylogeny of the relevant taxa with estimated divergence times, but recent progress in molecular (Thorne and Kishino, 2002; Sanderson, 2003; Brochu, 2004) and paleontological dating (Marjanović and Laurin, 2007, 2008) should facilitate this in the future. This is already shown by large compilations of time-calibrated trees (e.g. Hedges and Kumar, 2009). Studying floral biodiversity of the paleo- and neotropics using the PDI would allow testing of the various hypotheses formulated above to explain the apparently greater biodiversity of the neotropics than the paleotropics.

All this raises serious questions about the validity of long-admitted biodiversity patterns shown by paleontological and neontological examples. Many classical paleontological studies about the evolution of biodiversity through the Phanerozoic have been done at the family (e.g. Raup, 1979; Raup and Sepkoski, 1984) or genus level (Raup and Boyajian, 1988). Bertrand et al. (2006: 150) reviewed several such studies and pointed out that the most comprehensive paleontological databases that have been used to study the evolution of biodiversity are still compiled at the genus or family level. Various neontological studies about diversification have assessed dominance (the proportion of taxa at a given rank present in a single taxon of a higher rank, among a taxon of a still higher rank) and have argued that the 'hollow curve distribution' (HCD) implies that 
'one clade (or several clades) has had many more speciation events and/or fewer extinctions than other clades at the same taxonomic level' (Dial and Marzluff, 1989: 26). That would be interesting (it would translate into a higher diversification rate) if taxa of a given rank were monophyletic and had equal geological ages, but neither is required by rank-based nomenclature, and neither is true in the vast majority of taxonomies. Even though monophyly is increasingly enforced by authors and the lack of monophyly of taxa has been described as one of the greatest limitations of the use of taxonomies to assess biodiversity (Gaston and Williams, 1993: 5), some authors still claim that monophyly should not be required (e.g. Stuessy and König, 2008), and the commissions responsible for emending the rank-based codes refuse to enforce monophyly as a taxonomic requirement (Laurin, 2008: 224). Yet, the adverse effects of using paraphyletic taxa were clearly shown, among other examples by Patterson and Smith (1987), in the context of assessing cyclicity in extinction patterns. Until dominance and HCD are reassessed on clades of equal geological age (regardless of absolute rank), the significance of these patterns will remain unknown.

\section{An explanation of the persistence of Linnaean cat- egories in biological nomenclature}

The way the codes of rank-based nomenclature handle Linnaean categories assumes that these categories are purely artificial, since a given clade (which is a real entity, although it is imperfectly known) can be assigned any of several ranks by a systematist. Thus, the ICZN (1999) does not provide any rules to determine what constitutes a family (or any other absolute rank), beyond the fact that it is a higher-ranking entity than a genus, and a lower-ranking entity than an order.

As previously mentioned (Laurin, 2008), this is a way to avoid precise delimitation of taxonomic terms. It could be argued that taxonomic names ruled by the ICZN are not technical terms (Laurin, 2009), since such terms should designate a stable meaning (Lerat, 1995: 45; Calberg-Challot et al., 2010), and the rules of the ICZN seem to be aimed at achieving the opposite (a meaning that can be modified indefinitely). Rank-based nomenclature thus seems to be isolated in science in attempting to be deliberately vague about the meaning of its terms; the contrary is usually sought in other fields, such as geopolitics, geochronology, physics, and chemistry (Laurin, 2008).
It could be argued that most sciences (e.g. physics and chemistry) deal with universals (classes), whereas biological nomenclature deals with individuals. However, other sciences dealing with individuals (such as geopolitics) promote nomenclatural systems that precisely delimit entities (e.g., the borders of countries are precisely defined). Even the naming of individuals in our societies is designed to lead to names that unambiguously designate individuals (but given the large number of humans, our birth certificates need to include names of parents and place and date of birth to ensure unambiguous identification). Furthermore, until recently, most systematists viewed taxa as classes. This view changed when Ghiselin (1974) argued that species were individuals, and when this conclusion was extended to higher taxa (e.g. De Queiroz, 1992). Some authors still view taxa as classes, or consider taxa some kind of intermediate entity called homeostatic property clusters or HPCs (Rieppel, 2005). The claim that higher taxa are HPCs has been disputed (Ereshefsky, 2007), but as long as it retains adepts, it cannot be dismissed. Thus, the fact that taxa are viewed as individuals by many systematists does not explain why rank-based nomenclature promotes imprecision in delimitation; presumably, tradition plays a major role in this (Laurin, 2008).

The weight of tradition in retaining a nomenclatural system which effectively prevents precise delimitation of taxa becomes apparent in light of the history of rank-based nomenclature. When RN was first formalized (Strickland et al., 1843), most English-speaking biologists were still creationists and fixists; French-speaking systematists may have included a greater proportion of evolutionists because of the influence of Lamarck (1809) and St-Hilaire, but they were not represented in the commission that drafted the Strickland code. Even evolutionists, like Charles Darwin himself, who was on the commission that drafted the Strickland code, admitted that too little was known about the phylogeny to use it to delimit taxa. Subsequently, that system of nomenclature became so entrenched in tradition, because it was the only one in wide use and ruled by a code, that most systematists now take it for granted, and even become very upset when the possibility of changing it is evoked (Laurin, 2008: 227)

\section{Conclusion}

No objective criterion can be used to assign ranks to taxa, and even attempts at applying such a system have 
been rare and unsuccessful (Hennig, 1966, 1981). Ranks are devoid of objective reality and are 'ontologically empty designations' (Ereshefsky, 2002: S309); therefore, they should be dropped. Because RN is based on non-existent ranks (and types, which fortunately are real), it should be replaced by a more natural system. This includes PN (De Queiroz and Gauthier, 1990, 1992), but also any other system that does not rely on subjective Linnaean categories (e.g. Papavero et al., 2001; Kluge, 2004: 6-13; Dubois, 2005a, b; Béthoux, 2007). This was not done earlier because biological nomenclature must be regulated, or communication would be very difficult (Strickland et al., 1843), and until very recently, no viable alternative to RN existed. Such an alternative is now available: the ICPN (International Code of Phylogenetic Nomenclature; also known as the PhyloCode) is a complete, coherent implementation of PN. Drafts have been accessible on the Internet since 2000, and it has been updated regularly (the current version is $4 \mathrm{c}$ and dates from January 12,2010). Development of the ICPN has been supervised by an international society (ISPN) inaugurated in 2004 (Laurin and Cantino, 2004). Since then, that society convened twice more (Laurin and Cantino, 2007; Laurin and Bryant, 2009) to fine-tune the ICPN. The ISPN is open to all systematists, and it recently joined the IUBS (International Union of Biological Sciences; http://www.iubs. org/), an organization to which the societies or organizations that produce the rank-based codes (ICZN, ICBN; International Commission for the Nomenclature of Cultivated Plants, etc.) also belong. Now, dropping ranks without generating nomenclatural chaos becomes possible, and the natural taxonomy that Linnaeus, Darwin and many others dreamt about is finally in sight.

\section{Acknowledgements}

I thank A. Dubois for bibliographic information and D. Marjanović for comments on the draft. N.J. Kluge and two anonymous reviewers provided detailed comments that helped improve the paper, even though I could not follow some of them because of disagreements on basic issues.

\section{References}

Alroy J. 2002. How many named species are valid? Proceedings of the National Academy of Sciences of the United States of America 99: 3706-3711. doi:10.1073/pnas.062691099.
Andersen AN. 1995. Measuring more of biodiversity: Genus richness as a surrogate for species richness in Australian ant faunas. Biological Conservation 73: 39-43.

Avise JC, Johns GC. 1999. Proposal for a standardized temporal scheme of biological classification for extant species. Proceedings of the National Academy of Sciences of the United States of America 96: 7358-7363.

Avise JC, Mitchell D. 2007. Time to standardize taxonomies. Systematic Biology 56: 130-133. doi:10.1080/10635150601145365

Benton MJ. 2007. The Phylocode: Beating a dead horse? Acta Palaeontologica Polonica 52: 651-655.

Benton MJ, Donoghue PCJ. 2007. Paleontological evidence to date the tree of life. Molecular Biology and Evolution 24: 26-53. doi:10.1093/molbev/msl150

Benton MJ, Tverdokhlebov VP, Surkov MV. 2004. Ecosystem remodelling among vertebrates at the Permian-Triassic boundary in Russia. Nature 432: 97-100. doi:10.1038/nature 02950

Bertrand Y, Pleijel F, Rouse GW. 2006. Taxonomic surrogacy in biodiversity assessments, and the meaning of Linnaean ranks. Systematics and Biodiversity 4: 149-159. doi:10.1017/ S1477200005001908

Béthoux O. 2007. Propositions for a character-state-based biological taxonomy. Zoologica Scripta 36: 409-416. doi: 10.1111/j.1463-6409.2007.00287.x

Béthoux O. 2010. Optimality of phylogenetic nomenclatural procedures. Organisms, Diversity and Evolution 10: 173191. doi:10.1007/s13127-010-0005-3

Bininda-Emonds ORP, Cardillo M, Jones KE, MacPhee RDE, Beck RMD, Greyner R, Price SA, Vos RA, Gittleman JL, Purvis A. 2007. The delayed rise of present-day mammals. Nature 446: 507-512. doi:10.1038/nature05634

Brochu CA. 2004. Patterns of calibration age sensitivity with quartet dating methods. Journal of Paleontology 78: 7-30.

Brochu CA, Sumrall CD. 2001. Phylogenetic nomenclature and paleontology. Journal of Paleontology 75: 754-757.

Bromham L. 2003. Molecular clocks and explosive radiations. Journal of Molecular Evolution 57: S13-S20. doi:10.1007/ s0023 9-003-0002-7

Bush GL. 2007. Speciation, process of. Pp. 371-381 in: Encyclopedia of Biodiversity 5. San Diego: Academic Press.

Calberg-Challot M, Lerat P, Roche C. 2010. Quelle place accorder aux corpus dans la construction d'une terminologie? Pp. 33-52 in: Roche C, ed., TOTh 2009. Annecy, France: Institut Porphyre.

Cantino PD. 2004. Classifying species versus naming clades. Taxon 53: 795-798.

Cantino PD, De Queiroz K. 2010. International Code of Phylogenetic Nomenclature. Version 4c. http://www.ohiou.edu/ phylocode/

Cantino PD, Olmstead RG, Wagstaff SJ. 1997. A comparison of phylogenetic nomenclature with the current system: a botanical case study. Systematic Biology 46: 313-331.

Carroll RL. 1988. Vertebrate Paleontology and Evolution. New York: W. H. Freeman.

Cubo J. 2003. Evidence for speciational change in the evolution of ratites (Aves: Palaeognathae). Biological Journal of the Linnean Society 80: 99-106.

Desdevises Y, Legendre P, Azouzi L, Morand S. 2003. Quantifying phylogenetically structured environmental variation. Evolution 57: 2467-2652. 
Dial KP, Marzluff JM. 1989. Nonrandom diversification within taxonomic assemblages. Systematic Zoology 38: 26-37.

De Queiroz K. 1992. Phylogenetic definitions and taxonomic philosophy. Biology and Philosophy 7: 295-313.

De Queiroz K. 1998 The general lineage concept of species, species criteria, and the process of speciation. Pp. 57-75 in: Howard DJ, Berlocher SH, eds, Endless Forms: Species and Speciation. Oxford: Oxford University Press.

De Queiroz K, Cantino PD. 2001. Phylogenetic nomenclature and the PhyloCode. Bulletin of Zoological Nomenclature 58: 254-271.

De Queiroz K, Donoghue, MJ. 1988. Phylogenetic systematics and the species problem. Cladistics 4: 317-388.

De Queiroz K, Gauthier J. 1990. Phylogeny as a central principle in taxonomy: Phylogenetic definitions of taxon names. Systematic Zoology 39: 307-322.

De Queiroz K, Gauthier J. 1992. Phylogenetic taxonomy. Annual Review of Ecology and Systematics 23: 449-480.

Dubois A. 1988. Le genre en zoologie: essai de systématique théorique. Mémoires du Muséum National d'Histoire Naturelle 139: 1-124.

Dubois A. 2005a. Proposals for the incorporation of nomina of higher-ranked taxa into the Code. Bulletin of Zoological Nomenclature 62: 200-209.

Dubois A. 2005b. Proposed Rules for the incorporation of nomina of higher-ranked zoological taxa in the International Code of Zoological Nomenclature. 1. Some general questions, concepts and terms of biological nomenclature. Zoosystema 27: 365-426.

Dubois A. 2006. New proposals for naming lower-ranked taxa within the frame of the International Code of Zoological Nomenclature. Comptes Rendus Biologies 329: 823-840. doi:10.1016/j.crvi.2006.07.003

Dubois A. 2007a. Phylogeny, taxonomy and nomenclature: the problem of taxonomic categories and of nomenclatural ranks. Zootaxa 1519: 27-68.

Dubois A. 2007b. Naming taxa from cladograms: a cautionary tale. Molecular Phylogenetics and Evolution 42: 317-330. doi:10.1016/j.ympev.2006.06.007

Dyke GJ. 2002. Should paleontologists use 'Phylogenetic' nomenclature? Journal of Paleontology 76: 793-796.

Ereshefsky M. 2002. Linnaean ranks: Vestiges of a bygone era. Philosophy of Science 69: S305-S315.

Ereshefsky M. 2007. Foundational issues concerning taxa and taxon names. Systematic Biology 56: 259-301. doi:10.1080 $/ 10635150701317401$

Erwin D, Valentine JW, Jablonski D. 1997. The origin of animal body plans. American Scientist 85: 126-137.

Excoffier L, Ray N. 2008. Surfing during population expansions promotes genetic revolutions and structuration. Trends in Ecology and Evolution 23: 347-351. doi:10.1016/j.tree.2008. 04.004

Faith DP. 1992. Conservation evaluation and phylogenetic diversity. Biological Conservation 61: 1-10.

Felsenstein J. 1985. Phylogenies and the comparative method. The American Naturalist 125: 1-15.

Frost DR, Grant T, Faivovich J, Bain RH, Haas A, Haddad CFB, de Sá RO, Channing A, Wilkinson M, Donnellan SC, Raxworthy CJ, Campbell JA, Blotto B, Moler P, Drewes RC, Nussbaum RA, Lynch JD, Green DM, Wheeler WC. 2006.
The amphibian tree of life. Bulletin of the American Museum of Natural History 297: 1-370.

Gaston KJ, Williams PH. 1993. Mapping the world's speciesthe higher taxon approach. Biodiversity Letters 1: 2-8.

Ghiselin MT. 1974. A radical solution to the species problem. Systematic Zoology 23: 536-544.

Goloboff PA, Mattoni CI, Quinteros AS. 2008. TNT, a free program for phylogenetic analysis. Cladistics 24: 774-786.

Gradstein FM, Ogg JG, Smith AG. 2004. A Geologic Time Scale 2004. Cambridge: Cambridge University Press.

Grelle CEV. 2002. Is higher-taxon analysis an useful surrogate of species richness in studies of Neotropical mammal diversity? Biological Conservation 108: 101-106.

Greuter W, McNeill J, Barrie FR, Burdet HM, Demoulin V, Filgueiras TS, Nicolson DH, Silva PC, Skog JE, Trehane P, Turland NJ, Hawksworth DL. 2000. International Code of Botanical Nomenclature. Königstein (Germany): Koeltz Scientific Books.

Griffiths GCD. 1974. On the foundations of biological systematics. Acta Biotheoretica 23: 85-131.

Griffiths GCD. 1976. The future of Linnaean nomenclature. Systematic Biology 25: 168-173.

Hedges SB, Kumar S. 2009. Discovering the timetree of life. Pp. 3-18 in: Hedges SB, Kumar S, eds, The Timetree of Life. New York: Oxford University Press.

Hennig W. 1966. Phylogenetic systematics. Urbana: University of Illinois Press.

Hennig W. 1981. Insect Phylogeny. Chichester: John Wiley and Sons.

Hillis DM, Wilcox TP. 2005. Phylogeny of the New World true frogs (Rana). Molecular Phylogenetics and Evolution 34: 299-314. doi:10.1016/j.ympev.2004.10.007

Hu Y, Meng J, Wang Y, Li C. 2005. Large Mesozoic mammals fed on young dinosaurs. Nature 433: 149-152. doi:10.1038/ nature 03102

Hugall AF, Foster R, Lee MSY. 2007. Calibration choice, rate smoothing, and the pattern of tetrapod diversification according to the long nuclear gene RAG-1. Systematic Biology 56: 543-563. doi:10.1080/10635150701477825

International Commission on Zoological Nomenclature. 1999. International Code of Zoological Nomenclature, Fourth ed. London: The International Trust for Zoological Nomenclature

Josse S, Moreau T, Laurin M. 2006. Stratigraphic tools for Mesquite. http://mesquiteproject.org/packages/stratigraphicTools/

Kluge NJ. 2004. The phylogenetic system of Ephemeroptera. Dordrecht (The Netherlands): Kluwer Academic Publishers.

Kriloff A, Germain D, Canoville A, Vincent P, Sache M, Laurin M. 2008. Evolution of bone microanatomy of the tetrapod tibia and its use in palaeobiological inference. Journal of Evolutionary Biology 21: 807-826. doi:10.1111/j.1420-9101. 2008.01512.x

Lamarck JB. 1809. Philosophie zoologique. Paris: Flammarion.

Lapage SP, Sneath PHA, Lessel EF, Skerman VBD, Seeliger HPR, Clark WA. 1990. International Code of Nomenclature of Bacteria (1990 revision). http://www.ncbi.nlm.nih.gov/ bookshelf/br.fcgi?book=icnb\&part=A185

Laurin M. 2004. The evolution of body size, Cope's rule and the origin of amniotes. Systematic Biology 53: 594-622. doi: 10.1080/10635150490445706 
Laurin M. 2005. The advantages of phylogenetic nomenclature over Linnean nomenclature. Pp. 67-97 in: Minelli A, Ortalli G, Sanga G, eds, Animal Names, Vol. 1. Venice: Instituto Veneto di Scienze, Lettere ed Arti.

Laurin M. 2008. The splendid isolation of biological nomenclature. Zoologica Scripta 37: 223-233. doi:10.1111/j.14636409.2007.00318.x

Laurin M. 2009. La nomenclature biologique aujourd'hui: que reste-t-il de Linné ? Pp. 1-16 in: Roche C, ed., TOTh 2009. Annecy (France): Institut Porphyre.

Laurin M, Bryant HN. 2009. Third Meeting of the International Society for Phylogenetic Nomenclature: a Report. Zoologica Scripta 38: 333-337. doi:10.1111/j.1463-6409.2008.00379.x

Laurin M, Cantino PD. 2004. First international phylogenetic nomenclature meeting: a report. Zoologica Scripta 33: 475479.

Laurin M, Cantino, PD. 2007. Second meeting of the International Society for Phylogenetic Nomenclature: a report. Zoologica Scripta 36: 109-117. doi:10.1111/j.1463-6409.2006. 00268.x

Laurin M, Reisz RR. 1990. Tetraceratops is the oldest known therapsid. Nature 345: 249-250.

Lee MSY. 2003. Species concepts and species reality: salvaging a Linnaean rank. Journal of Evolutionary Biology 16: 179188.

Lee MSY, Doughty P. 2003. The geometric meaning of macroevolution. Trends in Ecology and Evolution 18: 263-266.

Lee MSY, Skinner A. 2007. Stability, ranks, and the PhyloCode. Acta Palaeontologica Polonica 52: 643-650.

Lerat P. 1995. Les langues spécialisées. Paris: Presses Universitaires de France.

Lherminier P. 2009. Le mythe de l'espèce. Paris: Ellipses.

Lim BK. 2007. Divergence times and origin of neotropical sheath-tailed bats (Tribe Diclidurini) in South America. Molecular Phylogenetics and Evolution 45: 777-791. doi:10.1016/j.ympev.2007.09.003

Linnaeus C. 1758. Systema naturae, $10^{\text {th }}$ ed. Stockholm: Holmiae (Laurentii Salvii).

Maddison WP, Maddison DR. 2009. Mesquite: a modular system for evolutionary analysis, version 2.71 . http://mesquiteproject.org

Marjanović D, Laurin M. 2007. Fossils, molecules, divergence times, and the origin of lissamphibians. Systematic Biology 56: 369-388. doi:10.1080/10635150701397635

Marjanović D, Laurin M. 2008. Assessing confidence intervals for stratigraphic ranges of higher taxa: the case of Lissamphibia. Acta Palaeontologica Polonica 53: 413-432.

Mattila TM, Bokma F. 2008. Extant mammal body masses suggest punctuated equilibrium. Proceedings of the Royal Society of London, Series B 275: 2195-2199. doi:10.1098/ rspb.2008.0354

Mayr E, Ashlock PD. 1991. Principles of Systematic Zoology. New York: McGraw-Hill.

McHugh D. 1997. Molecular evidence that echiurans and pogonophorans are derived annelids. Proceedings of the $\mathrm{Na}$ tional Academy of Sciences of the United States of America 94: 8006-8009.

McShea DW. 2000. Trends, tools and terminology. Paleobiology 26: 330-333.

Minelli A. 2000. The ranks and the names of species and higher taxa, or a dangerous inertia of the language of natural history. Pp. 339-351 in: Ghiselin MT, Leviton AE, eds, Cultures and Institutions of Natural History: Essays in the History and Philosophy of Sciences. San Francisco: California Academy of Sciences.

Minelli A. 2007. Invertebrate taxonomy and evolutionary developmental biology. Zootaxa 1668: 55-60.

Moreno CE, Guevara R, Sánchez-Rojas G, Téllez D, Verdu JR. 2008. Community level patterns in diverse systems: A case study of litter fauna in a Mexican pine-oak forest using higher taxa surrogates and re-sampling methods. Acta Ecologica 33: 73-84. doi:10.1016/j.actao.2007.09.002

Padian K. 2008. Darwin's enduring legacy. Nature 451: 632634.

Papavero N, Llorente-Bousquets J, Abe JM. 2001. Proposal of a new system of nomenclature for phylogenetic systematics. Arquivos de Zoologia Museu de Zoologia da Universitade de São Paulo 36: 1-145.

Patterson C, Smith AB. 1987. Is the periodicity of extinctions a taxonomic artefact? Nature 330: 248-251.

Pilbeam D, Young N. 2004. Hominoid evolution: synthesizing disparate data. Comptes Rendus Palevol 3: 305-321. doi:10. 1016/j.crpv.2004.01.006

Pleijel F, Rouse GW. 2003. Ceci n'est pas une pipe: names, clades and phylogenetic nomenclature. Journal of Zoological Systematics and Evolutionary Research 41: 162-174.

Prance GT. 1994. A comparison of the efficacy of higher taxa and species numbers in the assessment of biodiversity in the Neotropics. Philosophical Transactions of the Royal Society, Series B 345: 89-99.

Purvis A, Agapow P-M. 2002. Phylogeny imbalance: Taxonomic level matters. Systematic Biology 51: 844-854. doi:10.1080/10635150290155809

Raup DM. 1979. Size of the Permo-Triassic bottleneck and its evolutionary implications. Science 206: 217-218.

Raup DM, Boyajian GE. 1988. Patterns of generic extinction in the fossil record. Paleobiology 14: 109-125.

Raup DM, Sepkoski JJ Jr. 1984. Periodicity of extinctions in the geologic past. Proceedings of the National Academy of Sciences of the United States of America 81: 801-805.

Rieppel O. 2005. Monophyly, paraphyly, and natural kinds. $B i$ ology and Philosophy 20: 465-487. doi:10.1007/s10539-0040679-z

Rowe T, Gauthier J. 1992. Ancestry, paleontology, and definition of the name Mammalia. Systematic Biology 41: 372378.

Sakamoto M, Lloyd GT, Benton MJ. 2010. Phylogenetically structured variance in felid bite force: the role of phylogeny in the evolution of biting performance. Journal of Evolutionary Biology 23: 463-478. doi:10.1098/rspb.2010.0794

Sanderson MJ. 2002. Estimating absolute rates of molecular evolution and divergence times: a penalized likelihood approach. Molecular Biology and Evolution 19: 101-109.

Sanderson MJ. 2003. r8s: inferring absolute rates of molecular evolution and divergence times in the absence of a molecular clock. Bioinformatics 19: 301-302.

Schmitz H, Uddenberg N, Östensson P. 2007. Linné - le rêve de l'ordre dans la nature (translated by M. Laurin). Paris: Belin.

Schuh RT. 2003. The Linnean system and its 250-year persistence. The Botanical Review 96: 59-78.

Semaw S, Simpson SW, Quade J, Renne PR, Butler RF, McIntosh WC, Levin N, Diominguez-Rodrigo M, Rogers MS. 
2005. Early Pliocene hominids from Gona, Ethiopia. Nature 433: 301-305. doi:10.1038/nature03177

Smith HF, Fisher RE, Everett ML, Thomas AD, Bollinger RR, Parker W. 2009. Comparative anatomy and phylogenetic distribution of the mammalian cecal appendix. Journal of EvolutionaryBiology22:1984-1999.doi:10.1111/j.1420-9101. 2009.01809.x

Strickland HE, Henslow JS, Phillips J, Shuckard WE, Richardson JB, Waterhouse GR, Owen R, Yarrell W, Jenyns L, Darwin C, Broderip WJ, Westwood JO. 1843. Series of propositions for rendering the nomenclature of zoology uniform and permanent, being the Report of a Committee for the consideration of the subject appointed by the British Association for the Advancement of Science. Annals and Magazine of natural History 11: 259-275.

Stuessy TF, König C. 2008. Patrocladistic classification. Taxon 58: 594-601.

Terlizzi A, Bevilacqua S, Fraschetti S, Boero F. 2003. Taxonomic sufficiency and the increasing insufficiency of taxonomic expertise. Marine Pollution Bulletin 46: 556-561. doi:10.1016/S0025-326X(03)00066-3

Thorne JL, Kishino H. 2002. Divergence time and evolutionary rate estimation with multilocus data. Systematic Biology 51: 689-702. doi:10.1080/10635150290102456

Tinn, O, Oakley TH. 2008. Erratic rates of molecular evolution and incongruence of fossil and molecular divergence time estimates in Ostracoda (Crustacea). Molecular Phylogenetics and Evolution 48: 157-167. doi:10.1016/j.ympev.2008. 03.001

Turelli M, Barton NH, Coyne JA. 2001. Theory and speciation. Trends in Ecology and Evolution 16: 330-343.
Valentine JW. 2004. On the Origin of Phyla. Chicago: University of Chicago Press.

Van Valen L. 1973. Are categories in different phyla comparable? Taxon 22: 333-373.

Venditti C, Pagel M. 2010. Speciation as an active force in promoting genetic evolution. Trends in Ecology and Evolution 25: 14-20. doi:10.1016/j.tree.2009.06.010

Ward P, Labandeira C, Laurin M, Berner R. 2006. Confirmation of Romer's Gap as a low oxygen interval constraining the timing of initial arthropod and vertebrate terrestrialization. Proceedings of the National Academy of Sciences of the United States of America 103: 16818-16822. doi:10.1073/ pnas.0607824103

Wible JR, Rougier GW, Novacek MJ, Asher RJ. 2007. Cretaceous eutherians and Laurasian origin for placental mammals near the K/T boundary. Nature 447: 1003-1006. doi: 10.1038/nature 05854

Wills MA, Briggs DEG, Fortey RA. 1994. Disparity as an evolutionary index: a comparison of Cambrian and Recent arthropods. Paleobiology 20: 93-130.

Wilson DE, Reeder DM, eds, 2005. Mammal Species of the World: A Taxonomic and Geographic Reference. Baltimore: Johns Hopkins University Press.

Received: 1 June 2010

Revised and accepted: 31 August 2010

Published online: 20 October 2010

Editor: J.W. Arntzen 